\title{
Bone in CKD, a Fascinating Evolving Topic
}

\author{
J. Cannata-Andía ${ }^{1}$ N N. Carrillo-López ${ }^{1} \cdot$ A. Ferreira ${ }^{2}$
}

Received: 25 January 2021 / Accepted: 30 January 2021 / Published online: 6 April 2021

(C) The Author(s), under exclusive licence to Springer Science+Business Media, LLC part of Springer Nature 2021

In 1943, the term renal osteodystrophy was used for the first time to group four histological lesions found in patients with chronic kidney disease (CKD): osteitis fibrosa, osteomalacia, osteoporosis and osteopetrosis [1]. During the following 20 years this term was not used in clinical practice due to the lack of precise and specific non-invasive diagnostic methods to evaluate these alterations. In the late $60^{\prime}$ and $70^{\prime}$, the measurement of key biochemical parameters such as parathyroid hormone (PTH) became available [2], the imaging diagnosis techniques improved [3] and the analysis of undecalcified bone became possible to better interpret the bone biopsies [4].

All these progresses allowed to improve the study of the bone and mineral disorders associated to CKD; thus, the term renal osteodystrophy begun to play a role in the daily management of the CKD mineral and bone disorders. During the late $70^{\prime}$ and in the $80^{\prime}$, the aluminium bone disease helped to put in the first line the importance of the bone abnormalities in CKD outcomes [5, 6].

In 2006, six decades after the first use of the term renal osteodystrophy, a new term, Chronic Kidney Disease-Mineral and Bone Disorders (CKD-MBD), was coined to group a more complex clinical syndrome which includes biochemical and bone abnormalities of CKD plus other currently associated complications such as vascular calcification, cardiovascular abnormalities and bone fragility fractures [7]. Since then, the term renal osteodystrophy was reserved for the bone histological diagnosis of the CKD-MBD, based on parameters of bone turnover, mineralization and volume. Contemporarily, new players such as fibroblast growth factor

J. Cannata-Andía

cannata@hca.es

1 Bone and Mineral Research Unit, Hospital Universitario Central de Asturias, Instituto de Investigación Sanitaria del Principado de Asturias (ISPA), Universidad de Oviedo, Retic REDinREN-ISCIII, Avda. Roma, sn., 33011 Oviedo, Spain

2 Nephrology Department, Centro Hospitalar e Universitário de Lisboa Central, Nova Medical School, Nova University, Lisbon, Portugal
23 (FGF23) and Klotho entered the scenario of the pathogenesis of this syndrome.

The first paper of this special issue (SI) of Calcified Tissue International and Musculoskeletal Research journal updates the pathogenesis and management of CKD-MBD [8]. The interrelated effects of phosphorus, calcium, FGF23, PTH, the vitamin D hormonal system and Klotho are extensively discussed. The molecular mechanisms by which the main regulators of the parathyroid function exert their actions through their specific receptors are discussed [8], serving as a base to better understand the mechanisms of action of the therapies available for CKD discussed in one specific review of this SI.

Santos et al. address the impact of the CKD-MBD in children, describing the impact of progression and severity of the multifactorial growth impairment observed clinically and experimentally and the different strategies to optimise growth in CKD [9]. During last years, both in adults and children, several pathways and factors have emerged as important players in the maintenance of the bone and vascular health. Among them, inflammation, oxidative stress, the immunological ageing and the RANK/RANKL/OPG and Wnt/ßcatenin systems, discussed by Carrillo-López et al. play an important role in the relationship between bone loss and progression of vascular calcification observed in CKD patients [10].

Despite that bone has recognized properties allowing mobilization of minerals from bone and protection of vital organs, Mazzaferro et al. hypothesize about new important biological osteoimmune functions of the bone marrow, attributing to it several of the immune/inflammatory bone responses that can partly explain some bone and vessel alterations associated to CKD and ageing [11]. The chemokines, members of the cytokines family, could influence the bone marrow niche impacting on bone formation and resorption. The bone could be considered as an inner sensor placed in the middle of the immune and inflammatory response associated to the accelerated ageing.

The chemokines may be not only linking bone and inflammation, but also may have importance in the connections 
between muscle and bone. This important aspect is discussed by Leal et al. emphasizing the mechanisms involved in this bone-muscle interaction in which myokines and osteokines are implicated as part of the skeletal-muscle secretome [12]. This topic has attracted great interest due to the high prevalence of muscle and protein/energy wasting and sarcopenia observed in the CKD patients.

In bone health, the synthesis and regulation of the bone matrix plays a key role. Osteocalcin and the matrix Gla protein are activated by vitamin $\mathrm{K}$, which modulates the carboxylation of osteocalcin to convert it in the fully functional form. As vitamin $\mathrm{K}$ is deficient in CKD, Fusaro et al. address the likely role of this deficiency in bone fragility [13]. The review details the actions of phylloquinone (K1) and menaquinone (K2), the two forms of vitamin K, clarifying the role of vitamin $\mathrm{K} 2$ on the microbiota and gut dysbiosis observed in CKD. The likely protective role of vitamin $\mathrm{K}$ supplementation together with the negative effects of vitamin $\mathrm{K}$ antagonists in the occurrence of bone fragility fractures are discussed.

Although the diagnosis of CKD-MBD in the current clinical practice is mainly based on non-invasive and worldwide available biochemical and imaging techniques, the gold standard for the diagnosis of CKD bone disease is the bone biopsy. The current classification of renal osteodystrophy, the advantages and limitations, and the present role of the bone biopsy in CKD-MBD are detailed by Ferreira et al. [14].

CKD-MBD comprise several coincident alterations; however, there are three main modifiable factors involved in the pathogenesis of the parathyroid dysfunction and their complications: the disturbances of phosphate, calcium and vitamin $\mathrm{D}$ metabolism. The role of the main drugs used in the management of CKD-MBD, vitamin D, calcimimetics and phosphate binders are extensively discussed by Komaba et al. [15].

In CKD-MBD there is a growing interest for the osteoporotic component [16]; this is related to several factors such as a greater survival of CKD patients, the progresses in renal replacement therapies (RRT), a higher life expectancy and a greater access to the RRT [17]. Some of the risk factors for the CKD osteoporosis, also called "Uremic Osteoporosis" [18], are the same as the general population, but others are inherent to CKD and also secondary to the therapies used in this condition; this topic is addressed by Skou Jørgensen et al. [19].

One of the most important challenges in CKD osteoporosis is how to diagnose it using the same tools like in the general population. These aspects are discussed by Bover et al., and two phases need to be distinguished in the evolution of this aspect [20]. During the first phase, by the time the European, North American and global CKD-MBD guidelines were published [21-23], there were no data supporting that the measurement of bone mineral density (BMD) could predict bone fragility fractures in CKD, like in the general population. This concept progressively changed, as some new reports showed that BMD could also predict bone fractures in the CKD population [24-26].

Like in the general population, the main clinical consequence of CKD osteoporosis is the bone fragility fracture, as discussed by Pimentel et al. [27], reviewing the epidemiology and the management of this complication, emphasising the differences in the treatment choices, according to the stages of CKD.

Kidney transplantation offers the best quality of life and survival for those with end stage CKD, but despite these benefits, it is still a challenge to control the CKD-MBD after a transplantation. The difficulties are mainly due to the fact that patients who received a kidney transplant currently came from a long-term stay on dialysis therapy with important mineral and bone disturbances. After a successful kidney transplantation, many of them partly regress, but others remain, adding to some negative effects of the immunosuppressive therapy. All these aspects are discussed by Torregrosa et al. in the closing review of this SI [28].

We have been able to produce a SI with a comprehensive set of reviews of bone-related disorders in CKD. This was possible due to the efforts of a multidisciplinary group of scientists working in this area, who gathered in recent meetings aiming to improve the knowledge and the management of CKD-MBD and fostered the interaction among medical societies and foundations. The Guest Editors of this SI of Calcified Tissue International and Musculoskeletal Research are proud for this achievement and consider this SI a very fruitful collaboration of the ERA-EDTA (European Renal Association-European Dialysis and Transplant Association) CKD-MBD working group, EUROD (European Renal Osteodystrophy), and IOF (International Osteoporosis Foundation), hoping that this challenging enterprise will continue to further improve the management of mineral and bone disorders in CKD.

\section{Compliance with Ethical Standards}

Conflict of interest Cannata-Andía, Carrillo-López and Ferreira declare that they have no competing interests.

\section{References}

1. Liu SH, Chu HI (1943) Studies of calcium and phosphorus metabolism with special reference to pathogenesis and effects of dihydrotachysterol (A.T.10) and iron. Medicine 22(2):103-162 
2. Bricker NS et al (1969) Caclium, phosphorus, and bone in renal disease and transplantation. Arch Intern Med 123(5):543-553

3. Johnson C et al (1967) Roentgenographic manifestations of chronic renal disease treated by periodic hemodialysis. Am J Roentgenol Radium Ther Nucl Med 101(4):915-926

4. Cannata-Andía JB (2007) Changing the current terminology in medicine-always a challenge. Nephrol Dial Transpl 22(7):1811-1812

5. Berlyne GM et al (1972) Aluminium toxicity in rats. Lancet 1(7750):564-568

6. Kerr D, Ward M (1986) The history of aluminium related disease. In: Taylor Balliere Tindall GA (ed) Aluminium, and other trace elements in renal disease. Guilford, London, pp 1-14

7. Moe S et al (2006) Definition, evaluation, and classification of renal osteodystrophy: a position statement from Kidney Disease: Improving Global Outcomes (KDIGO). Kidney Int 69(11):1945-1953

8. Cannata-Andía JB et al (2020) Chronic kidney disease-mineral and bone disorders: pathogenesis and management. Calcif Tissue Int. https://doi.org/10.1007/s00223-020-00777-1

9. Santos F et al (2021) Bone disease in CKD in children. Calcif Tissue Int. https://doi.org/10.1007/s00223-020-00787-z

10. Carrillo-Lopez N et al (2021) Role of the RANK/RANKL/ OPG and Wnt/B-catenin systems in CKD Bone and cardiovascular disorders. Calcif Tissue Int. https://doi.org/10.1007/ s00223-020-00803-2

11. Mazzaferro S et al (2021) Inflammation, oxidative stress, and bone in chronic kidney disease in the osteoimmunology era. Calcif Tissue Int. https://doi.org/10.1007/s00223-020-00794-0

12. Leal DV et al (2021) Muscle-bone crosstalk in chronic kidney disease: the potential modulatory effects of exercise. Calcif Tissue Int. https://doi.org/10.1007/s00223-020-00782-4

13. Fusaro $\mathrm{M}$ et al (2021) Vitamin $\mathrm{K}$ in $\mathrm{CKD}$ bone disorders. Calcif Tissue Int. https://doi.org/10.1007/s00223-020-00792-2

14. Ferreira AC et al (2021) The role of bone biopsy in the management of CKD-MBD. Calcif Tissue Int. https://doi.org/10.1007/ s00223-021-00838-z

15. Komaba $\mathrm{H}$ et al (2021) Old and new drugs for the management of bone disorders in CKD. Calcif Tissue Int. https://doi.org/10.1007/ s00223-020-00788-y

16. Evenepoel P et al (2021) European Consensus Statement on the diagnosis and management of osteoporosis in chronic kidney disease stages G4-G5D. Nephrol Dial Transpl 36(1):42-59
17. Thomas B et al (2015) Maintenance dialysis throughout the world in years 1990 and 2010. J Am Soc Nephrol 26(11):2621-2633

18. Kazama JJ, Iwasaki Y, Fukagawa M (2013) Uremic osteoporosis. Kidney Int Suppl 3(5):446-450

19. Skou Jørgensen $\mathrm{H}$ et al (2021) Traditional and non-traditional risk factors for osteoporosis in CKD. Calcif Tissue Int. In press

20. Bover $\mathbf{J}$ et al (2021) The non-invasive diagnosis of bone disorders in CKD. Calcif Tissue Int. https://doi.org/10.1007/ s00223-020-00781-5

21. Cannata-Andía J, Passlick-Deetjen J, Ritz E (2000) Management of the Renal Patient. Nephrol Dial Transpl 15(suppl_5):1-154

22. Levey AS et al (2002) K/DOQI clinical practice guidelines for chronic kidney disease: evaluation, classification, and stratification. Am J Kidney Dis 39(2 Suppl 1):S1-266

23. Moe $\mathrm{S}$ et al, Kidney Disease: Improving Global Outcomes (KDIGO) CKD-MBD Work Group (2009) KDIGO clinical practice guideline for the diagnosis, evaluation, prevention, and treatment of Chronic Kidney Disease-Mineral and Bone Disorder (CKD-MBD). Kidney Int Suppl 113:S1-130

24. Ketteler M et al (2017) KDIGO 2017 clinical practice guideline update for the diagnosis, evaluation, prevention, and treatment of chronic kidney disease-mineral and bone disorder (CKD-MBD). Kidney Int Suppl (2011) 7(1): 1-59

25. Bucur RC et al (2015) Low bone mineral density and fractures in stages 3-5 CKD: an updated systematic review and meta-analysis. Osteoporos Int 26(2):449-458

26. West SL et al (2015) Bone mineral density predicts fractures in chronic kidney disease. J Bone Miner Res 30(5):913-919

27. Pimentel A et al (2020) Bone fragility fractures in CKD patients. Calcif Tissue Int. https://doi.org/10.1007/s00223-020-00779-Z

28. Torregrosa JV et al (2021) Bone mineral disease after kidney transplantation. Calcif Tissue Int. https://doi.org/10.1007/ s00223-021-00837-0

Publisher's Note Springer Nature remains neutral with regard to jurisdictional claims in published maps and institutional affiliations. 